\title{
Cyanophycin Granule Size Variation in Aphanocapsa
}

\author{
By MARIE E. DEMBINSKA† AND MARY M. ALLEN* \\ Department of Biological Sciences, Wellesley College, Wellesley, MA 02181, USA
}

(Received 22 May 1987; revised 23 September 1987)

\begin{abstract}
Techniques were developed for the rapid and simple electron microscopic visualization of isolated cyanophycin granules to allow analysis of their size from cells grown under different conditions. Granules were purified by differential and renografin density-gradient centrifugation from cells grown for various times in chloramphenicol-containing media, or in nitrogenlimited media to which nitrogen was then added back, or under light limitation. Granules were then observed by electron microscopy after staining with uranyl acetate, and random granule diameters were measured. Granule size increased significantly with time following chloramphenicol treatment and following light limitation. This suggests that much of the increase in amount of cyanophycin in cells treated with chloramphenicol or light limitation is caused by increase in granule size rather than in granule number. Insignificant changes in granule size were observed during nitrogen repletion, suggesting increase in granule number, not size.
\end{abstract}

\section{INTRODUCTION}

Cyanophycin granule polypeptide [CGP, multi-L-arginyl poly(L-aspartic acid)] is a nitrogen storage protein found uniquely in cyanobacteria (Allen \& Hutchison, 1980; Lawry \& Simon, 1982). It is a polymer, synthesized non-ribosomally, consisting of an equal molar ratio of arginine and aspartic acid (Simon, 1973b). Formation of this compound, which is usually found in a granular form (cyanophycin granules), is induced by starvation of nutrients other than nitrogen (Allen et al., 1980) and by addition of a number of growth-inhibitory agents such as chloramphenicol (CM) (Simon, 1973a; Lawry \& Simon, 1982).

The only published fine-structural studies of cyanophycin granules have been of thinsectioned material (Lang et al., 1972; Allen \& Weathers, 1980; Lawry \& Simon, 1982) or of freeze-fractured material (Allen \& Weathers, 1980). Little information is available on the mechanism of CGP synthesis such as peptide initiation, elongation and how and when granules increase in size. Allen \& Weathers (1980) showed small granules in thin sections of light-limited Aphanocapsa in late-exponential growth, whereas larger granules were observed in stationaryphase cells. In the present work, electron microscopic techniques were developed for rapid and easy observation of granule size variation. Granules isolated from Aphanocapsa 6308 at various times after CM treatment or after light limitation were then analysed since the amount of CGP increases rapidly under these conditions (Allen et al., 1980). Cyanophycin granules from nitrogen-limited and regreening cells were also observed for changes in size or appearance.

\section{METHODS}

Organism and growth. Aphanocapsa 6308 (Synechocystis ATCC 27150) was routinely grown with $5 \%(\mathrm{v} / \mathrm{v}) \mathrm{CO}_{2}$ in air in liquid medium no. 11 (Allen, 1968) as described previously (Allen \& Hutchison, 1980). CM $\left(5 \mu \mathrm{g} \mathrm{ml}^{-1}\right.$ ) was added in some experiments. In other experiments cells were grown in carboys containing 121 of medium no. 11

† Present address: Department of Microbiology and Molecular Biology, Tufts University, Boston, MA 02111, USA.

Abbreviations: CGP, cyanophycin granule polypeptide; CM, chloramphenicol. 


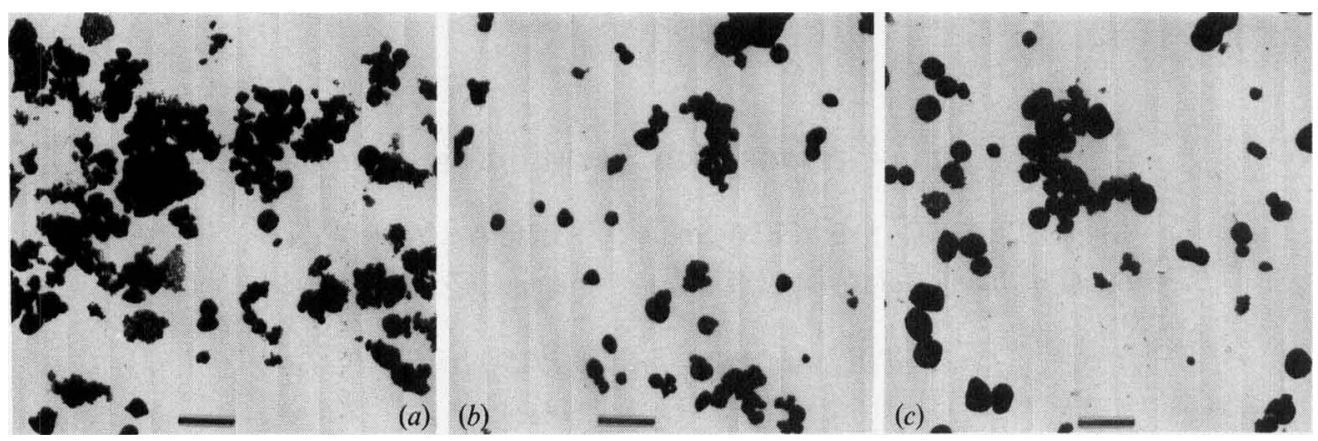

Fig. 1. Uranyl-acetate-stained purified cyanophycin granules isolated from Aphanocapsa grown under various conditions: $(a)$ from exponentially growing cells; $(b)$ from cells treated with CM for $12 \mathrm{~h} ;(c)$ from cells treated with $\mathrm{CM}$ for $48 \mathrm{~h}$. Bars, $1 \mu \mathrm{m}$.

with $1 / 40$ the normal concentration of $\mathrm{NaNO}_{3}$. After cells were starved for nitrogen, $\mathrm{NaNO}_{3}$ was added and samples were collected at various times, during regreening for granule isolation.

Cyanophycin granule isolation. At various times after treatments, cells were collected, disrupted using a French pressure cell (138 MPa pressure) and cyanophycin granules were purified. The $27000 \mathrm{~g}$ pellet, after a $15 \mathrm{~min}$ centrifugation of the crude extract, was washed with distilled water followed by $2 \%(\mathrm{v} / \mathrm{v})$ Triton X-100 before being resuspended in water and placed on $70-100 \%(\mathrm{v} / \mathrm{v})$ renografin step gradients (Allen \& Weathers, 1980). After $2 \mathrm{~h}$ at 18000 r.p.m. in a SW41 rotor, granule bands were removed, washed twice with distilled water and prepared for electron microscopy. Paper chromatography, after hydrolysis of this material (Allen \& Weathers, 1980), showed only arginine and aspartic acid to be present; quantitative analysis of the granule bands was done by the method of Simon (1973b).

Electron microscopy. Washed samples $(5 \mu \mathrm{l})$ from renografin gradients were placed on 300 -mesh copper grids for $3 \mathrm{~min}$. Excess liquid was removed and the grids were stained for $30 \mathrm{~s}$ with $1 \%(\mathrm{w} / \mathrm{v})$ uranyl acetate. The grids were observed with a Zeiss $9 \mathrm{~S}-2$ electron microscope operated at $60 \mathrm{kV}$. Random micrographs were taken and granule diameters were measured from enlarged prints. Significance of the results was determined using Duncan's test (Bruning \& Kintz, 1968).

\section{RESULTS}

Purified cyanophycin granules were observed from cells harvested before $(0 \mathrm{~h})$ and $6,12,24$ and $48 \mathrm{~h}$ after addition of CM. Fig. $1(a-c)$ shows representative fields of granules from these various sampling times. There was a marked increase in granule size with time after $\mathrm{CM}$ addition. Quantitative data are shown in Fig. 2. Mean granule diameter ranged from $181 \mathrm{~nm}$ (isolated from exponentially growing cells) to $446 \mathrm{~nm}$ (isolated from cells treated for $48 \mathrm{~h}$ with CM). Lack of overlap of the standard errors of the means shows that the differences observed in granule diameter are greater than any error that could result from inaccuracy in measurement between groups. Standard deviation of the mean values for each sampling showed a slight increase with time (data not shown), but the largest of the granules isolated from cells before $\mathrm{CM}$ treatment were smaller than the smallest of those $48 \mathrm{~h}$ after the addition of CM. Note the amorphous material associated with the granules isolated from exponentially growing cells (Fig. 1a).

Granules isolated from nitrogen-limited or regreening nitrogen-starved cells were difficult to purify. As observed for granules from exponentially growing cells (Fig. 1a), much amorphous material was associated with the granules throughout the purification process. The preparations were green throughout isolation. Fig. 3(a) shows purified material from cells starved for nitrogen for $98 \mathrm{~h}(0.3 \% \mathrm{CGP}$ on a dry weight basis). Fig. $3(b)$ shows granules purified from cells harvested $15 \mathrm{~h}$ after $\mathrm{NaNO}_{3}$ was added (3.4\% CGP on a dry weight basis).

Purified granules from cells grown to late-stationary phase ( $11 \mathrm{~d}$ growth) had a mean diameter of $1390 \mathrm{~nm}$ ( 245 randomly selected granules were measured), three times that of granules isolated from cells grown in CM for $48 \mathrm{~h}$. Fig. 3(c) shows an example of granules isolated from 


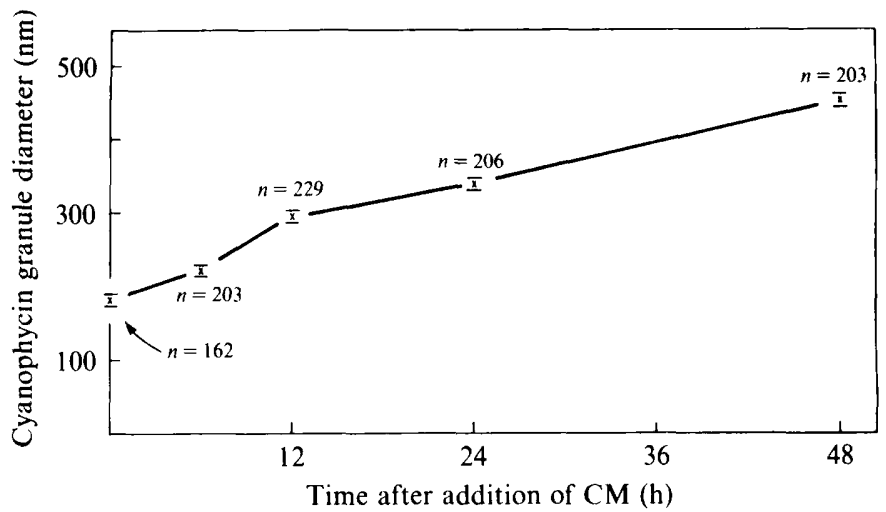

Fig. 2. Mean diameter of Aphanocapsa cyanophycin granules versus time after CM addition. Standard errors of the means are shown; $n=$ number of granules counted.

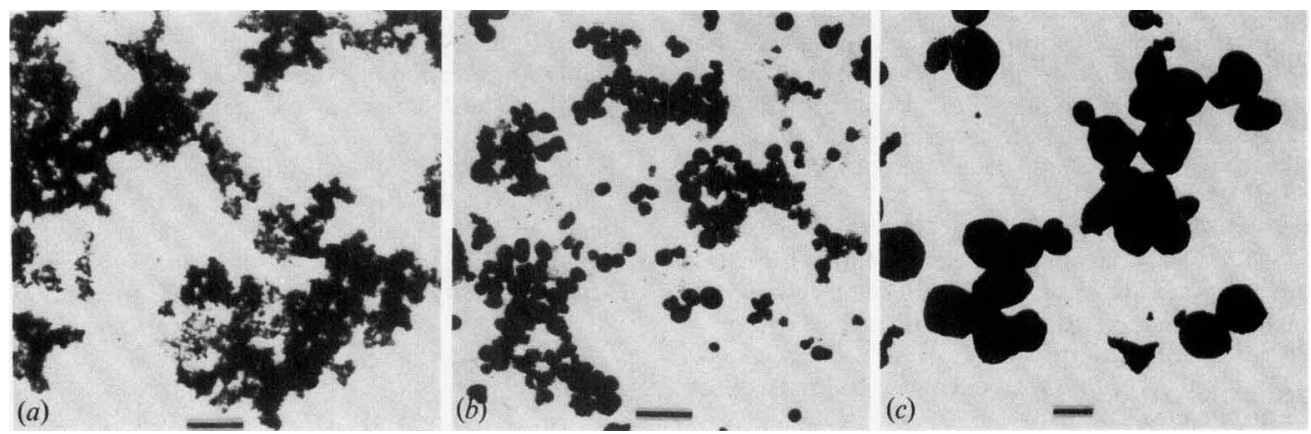

Fig. 3. Uranyl-acetate-stained purified cyanophycin granules from Aphanocapsa: (a) from cells starved for nitrogen for $98 \mathrm{~h} ;(b)$ from nitrogen-starved cells $15 \mathrm{~h}$ after $\mathrm{NaNO}_{3}$ was added; $(c)$ from light-limited (stationary-phase) cells. Bars $1 \mu \mathrm{m}$.

these light-limited cells. Much more variation in size was observed than in the granule populations isolated from CM-treated cells.

\section{DISCUSSION}

The present results indicate that increase in cyanophycin granule polypeptide in CM-treated and stationary-phase Aphanocapsa appears to be by an increase in granule size and not by an increase in de novo synthesis of granules.

When cells are growing exponentially under favourable conditions, CGP is present in low amounts, only $0.1 \%$ of the dry weight of the cell in Anabaena cylindrica (Simon, 1973a,b) or $1.5 \%$ in Aphanocapsa (Allen et al., 1980). When cells of Aphanocapsa were in light-limited stationary phase, CGP increased to $16 \%$ of the dry weight; cells treated with CM for $48 \mathrm{~h}$ accumulated CGP to $11 \%$ of their dry weight (Allen et al., 1980). Light-limited Calothrix marchica, observed in thin section, contained cyanophycin granules up to $740 \mathrm{~nm}$ in diameter (Tahmida Khan \& Godward, 1978), and analysis of thin sections of light-limited Aphanocapsa suggests that granules reach a diameter of $1900 \mathrm{~nm}$ (M. M. Allen, unpublished). This compares well with the mean of $1390 \mathrm{~nm}$ calculated in the present work. If the granules are assumed to be spherical, an increase in diameter from $181 \mathrm{~nm}$ to $446 \mathrm{~nm} 48 \mathrm{~h}$ after CM addition suggests approximately a 14-fold increase in volume. This amount compares well with the quantity of CGP shown to be present in CM-treated Aphanocapsa by chemical analysis (Allen et al., 1980). 
An immediate linear increase in CGP (measured by analysis of arginine content), followed by a decrease in amount, is seen in nitrogen-starved cells to which nitrate is added (Allen \& Hutchison, 1980). That no significant differences could be observed, over $30 \mathrm{~h}$, in the size of granules from such cells, although the amount of CGP increased tenfold, at $15 \mathrm{~h}$ after regreening began, suggests that new granules were formed under these conditions.

This work was supported by a William and Flora Hewlett Foundation Grant of Research Corporation; grants PCM 8311035 and R11 8211829 from the National Science Foundation; and by Wellesley College. The technical assistance of Leslie Killeen and Kirk Gasper is gratefully acknowledged.

\section{REFERENCES}

ALLEN, M. M. (1968). Simple conditions for growth of unicellular blue-green algae on plates. Journal of Phycology 4, 1-4.

Allen, M. M. \& Hawley, M. A. (1983). Protein degradation and synthesis of cyanophycin granule polypeptide in Aphanocapsa sp. Journal of Bacteriology 154, 1480-1484.

Allen, M. M. \& Hutchison, F. (1980). Nitrogen limitation and recovery in the cyanobacterium Aphanocapsa 6308. Archives of Microbiology 128, 1-7.

ALLEN, M. M. \& WeATHERS, P. J. (1980). Structure and composition of cyanophycin granules in the cyanobacterium Aphanocapsa 6308. Journal of Bacteriology 141, 959-962.

Allen, M. M., Hutchison, F. \& Weathers, P. J. (1980). Cyanophycin granule polypeptide formation and degradation in the cyanobacterium Aphanocapsa 6308. Journal of Bacteriology 141, 687-693.

BRUNing, J. L. \& KinTZ, B. L. (1968). Computational Handbook of Statistics. Glenview, Illinois: Scott Foresman \& Company.
LANG, N. J., Simon, R. D. \& Wolk, C. P. (1972). Correspondence of cyanophycin granules with structural granules in Anabaena cylindrica. Archiv für Mikrobiologie 83, 313-320.

LAWRY, N. H. \& Simon, R. D. (1982). The normal and induced occurrence of cyanophycin inclusion bodies in several blue-green algae. Journal of Phycology 18, 391-399.

Simon, R. D. (1973a). The effect of chloramphenicol on the production of cyanophycin granule polypeptide in the blue-green alga Anabaena cylindrica. Archiv für Mikrobiologie 92, 115-122.

Simon, R. D. (1973b). Measurement of the cyanophycin granule polypeptide content in the blue-green alga Anabaena cylindrica. Journal of Bacteriology 115, 1213-1216.

TAHMIDA Khan, Z. N. \& Godward, M. B. E. (1978). Cyanophycin granules in a blue-green algae Calothrix marchica Lemm. Current Science 47, 710-712. 